\title{
Preparation and characterization of porous crosslinked microspheres of new aromatic methacrylates
}

\author{
Marta Grochowicz • Barbara Gawdzik
}

Published online: 10 June 2012

(c) The Author(s) 2012. This article is published with open access at Springerlink.com

\begin{abstract}
The aim of this work was to prepare a new group of aromatic methacrylate monomers, utilise them in preparation of porous microspheres and study the influence of their chemical structure on the textural properties of porous methacrylate microspheres. Polymeric microspheres were prepared by suspension-emulsion polymerisation of four aromatic monomers: methacryloiloxybenzene, 1,2-dimethacryloiloxybenzene, 1,3-dimethacryloiloxybenzene and 1,4-dimethacryloiloxybenzene with another crosslinking agent-trimethylolpropane trimethacrylate. Mass median diameters of obtained beads are in the range $22-35 \mu \mathrm{m}$. The polymerisation reactions were carried out in the presence of a pore forming diluent. The influence of the diluent system on the porous structure of microspheres was studied in detail. To determine the textural properties of the studied microspheres, nitrogen adsorption-desorption and inverse sized exclusion chromatography measurements were used. Specific surface area of the obtained microspheres achieves value from 185 to $510 \mathrm{~m}^{2} / \mathrm{g}$. Since obtained polymeric materials can be used as chromatographic packings for HPLC their porous structure in a swollen state was investigated. Significant differences in the porous structure parameters for dry and swollen microspheres were observed.
\end{abstract}

Keywords Aromatic methacrylate monomers · Suspension-emulsion polymerisation · Microspheres · Porous polymers · Textural properties

M. Grochowicz $(\square) \cdot$ B. Gawdzik Department of Polymer Chemistry, Faculty of Chemistry, Maria Curie Sklodowska University, Gliniana Street 33, 20-614 Lublin, Poland

e-mail: mgrochowicz@umcs.pl

\section{Introduction}

The use of crosslinked homopolymers and copolymers in the shape of microspheres with tailor made properties is a topic of increasing activity and interest. Such materials are widely used as ion exchangers, polymeric adsorbents, polymeric stationary phases for chromatography, polymeric carriers for solid organic synthesis and immobilisation of enzymes [1-5]. Functional groups on the surface of polymeric microspheres determine their use. For chromatographic applications the morphological properties and the surface chemistry of particles should be appropriate for intended use. Functionality can be introduced onto the particle surface by applying functional monomers [6-9]. Aromatic methacrylates are highly reactive monomers due to the presence of the aromatic ring from one side and the ester group from another. Incorporation of multifunctional methacrylate monomers into the polymer network changes the selectivity of porous microspheres $[10,11]$.

Crosslinked polymeric microspheres with developed porous structure can be obtained with well known heterogeneous polymerisation methods such as suspension, emulsion or, quite new in relation to the previously mentioned, multi-step swelling polymerisation. Gawdzik et al. [12-15] proposed to use modified suspension polymerisation to produce permanently porous microspheres and called this method suspension-emulsion polymerisation. In contrast to suspension polymerisation, in this method the stabiliser of high molecular weight was replaced with a surfactant typical of emulsion polymerisation. The initiator of a radical reaction is soluble in the mixture of monomers. The diameters of microspheres synthesised by this method are in the range of $2-50 \mu \mathrm{m}$. The porous structure of microspheres formed in this way is generated by the use of 
pore-forming diluents. Appropriate selection of poreforming diluents allows obtaining microspheres with tailormade morphological properties [16, 17]. Kun and Kunin $[18,19]$ determined the influence of porogenic diluents on the porous structure of styrene-divinylbenzene copolymers indicating sol and nonsol diluents. However, it could be understood that for monomers other than ST and DVB the character of porogenic diluents can be different.

In this study, porous copolymeric microspheres were prepared from new synthesised aromatic methacrylate monomers: methacryloiloxybenzene (MB), 1,2-dimethacryloiloxybenzene (1,2DMB), 1,3-dimethacryloiloxybenzene (1,3DMB), 1,4-dimethacryloiloxybenzene (1,4DMB). The aim of our work was to investigate the influence of the chemical structure of monomers on the particle granulation, chemical structure and textural parameters of microspheres prepared with suspension-emulsion polymerisation.

\section{Experimental}

\subsection{Materials}

Methacryloyl chloride, decan-1-ol, triethylamine and bis (2-ethylhexyl)sulfosuccinate sodium salt (DAC, BP) were acquired from Fluka AG (Buchs Switzerland). Trimethylolpropane trimethacrylate (TRIM) and $\alpha, \alpha^{\prime}$-azoisobisbutyronitrile were obtained from Merck (Darmstadt, Germany). Phenol was from Loba Chemie (Wien, Austria). Resorcinol (benzeno-1,3-diol), benzeno-1,2-diol were from Fluka (product of Japan). Reagent grade acetone, methanol, chloroform, dichloromethane, toluene, hydroquinone and magnesium sulfate were from POCh (Gliwice, Poland).

THF used in inverse size exclusion chromatography (EC) experiments was HPLC-grade from Merck (Darmstadt, Germany). Alkylphenones and phthalates were laboratory-reagent-grade and were obtained from a number of sources. Polystyrene standards were obtained from Toyo Soda (Tokyo, Japan) and Merck.

\subsection{Methods of analysis}

Elemental analysis was made using a Perkin-Elmer CHN 2450 analyzer (Palo Alto, CA, USA). ${ }^{1} \mathrm{H}$ NMR spectra were recorded on a Bruker Avance 300 MSL instrument (Bruker, Germany) operating at the ${ }^{1} \mathrm{H}$ resonance frequency of $300 \mathrm{MHz}$. Chemical shifts were referred to deuterated chloroform serving as an internal standard. The ${ }^{13} \mathrm{C}$ NMR spectra of the compounds in deuterated chloroform were made using the same apparatus. Cross-polarisation magic angle spinning (CP-MAS ${ }^{13} \mathrm{C}$ NMR) measurements were completed on the same spectrometer at resonance frequency of $75.5 \mathrm{MHz}$. The number of scans was 2,048, and the spin rate was 7,300 Hz. TMS was used as the standard for the NMR experiments.

The Raman spectra of polymer samples were recorded using RENISHAW Raman Microscope (Renishaw, UK) equipped with microscope optical functions. The excited laser line was $785 \mathrm{~nm}$.

Gas chromatography/mass spectrometry (GC-MS) was made on a Thermo-Finnigan DSQ spectrometer (Finnigan, USA) hyphenated with a Trace GC-Ultra gas chromatograph equipped with a fused-silica RTX-5 capillary column $(20 \mathrm{~m} \times 0.18 \mathrm{~mm}$ I.D., film thickness $0.20 \mu \mathrm{m})$. The conditions were as follows: injector PTV-split 1:20, a temperature program of $35-320^{\circ} \mathrm{C}$ at a rate $20^{\circ} \mathrm{C} \mathrm{min}^{-1}$; MS electron ionization at $70 \mathrm{eV}$, ion volume temperature $220^{\circ} \mathrm{C}$.

FTIR spectra were determined on a Perkin Elmer 1700 Fourier transform infrared (FTIR) spectrometer with $\mathrm{KBr}$ pellets.

Average size and particle size distribution of the studied copolymers were determined using Mastersized Analyzer 2000 (Malvern Instruments, Worcestershire, United Kingdom). The statistic of the distribution was calculated using the derived diameters according to British standard BS2955: 1993.

The beads were examined using an atomic force (AFM) and scanning electron (SEM) microscopes. The images presented in this article were obtained from AFM Nanoscope III (Digital Instruments, USA) operating in contact mode. They contain $512 \times 512$ data points which were obtained within a few seconds. SEM micrographs were obtained from a BS-301 numerical scanning electron microscope (Czech Republic) with Satellite system digital picture detection.

\subsubsection{Chromatographic measurements}

Retention volumes of toluene, alkylphenones, phthalates and polystyrene standards were determined with a HewlettPackard HP-1050 liquid chromatograph equipped with a diode array UV detector, a Rheodyne 7125 injection valve with $20 \mu \mathrm{L}$ sample loop and a column packed with the copolymer. The column $(100 \mathrm{~mm} \times 4.1 \mathrm{~mm}$ I.D. $)$ was packed according to the procedure described previously [20].

In the EC measurements THF was the mobile phase at a flow rate of $1 \mathrm{~mL} / \mathrm{min}$. Each substance was injected separately as a $0.1 \%(\mathrm{v} / \mathrm{v})$ solution in THF. The given retention volumes were always the mean of three measurements.

\subsubsection{Porous structure characterization}

Porous structure of synthesised copolymers was characterized by using inverse size exclusion chromatography (EC) and nitrogen adsorption-desorption measurements. In dry state, the copolymers were characterized by means 
of an adsorption analyzer ASAP 2405 (Micrometrics Inc, USA). Determinations were based on the measurements of adsorption and desorption of nitrogen on the surface of the studied copolymer while cooling it with liquid nitrogen. The specific surface areas were calculated by the BET method (based on the theory of Brunauer, Emmet and Teller) for the nitrogen adsorption data in the range of a relative pressure $p / p_{o} 0.05-0.25$, assuming that the area of a single nitrogen molecule is $1.62 \mathrm{~nm}^{2}$ [21]. The total pore volume was estimated from a single point adsorption at a relative pressure of 0.985 . The pore size distributions were obtained from the desorption branch of the isotherm using the Barrett-Joyner-Halenda (BJH) procedure [22].

In a swollen state the copolymers were characterized by the EC technique introduced by Halasz and Martin [23]. The main assumption in this method is that in the good solvent chains of macromolecules form coils of a diameter corresponding to the polymer molecular weights. The diameter of the probe molecules $(\Phi$, in $\mathrm{nm})$ was calculated from the equation [24]:

$\Phi=0.062 M_{w}^{0.59}$

where $M_{w}$ is the gram-molecular weight of the probe. The diameter of the probe molecule is associated with a pore diameter $(\Phi)$ which corresponds to the smallest pore allowing unhindered access to the probe of a given molecular weight.

Exclusion chromatography experiments were carried out in THF using as pore-size probes, toluene, alkylphenones, phthalates and polystyrene standards with molecular weights ranging from 580 to $275,000[25,26]$.

The distribution coefficients $K_{O}$ (EC) were calculated according to the equation [24, 27]:

$K_{o}(\mathrm{EC})=\frac{V_{R}-V_{o}}{V_{p}}=\frac{V_{R}-V_{o}}{V_{i}-V_{o}}$

where: $V_{R}$-the retention volume of the probe; $V_{o}$-the interstitial volume equal to the retention volume of a totally excluded molecule; $V_{i}$ - the retention volume of a totally included molecule; $V_{p}=V_{i}-V_{o}$-the pore volume. The volume of micropores was calculated as the difference between the retention volume of dinonyl phthalate $(\Phi=$ $2.2 \mathrm{~nm}$ ) and toluene $(\Phi=0.9 \mathrm{~nm})$.

Swellability coefficients $B$ were determined by equilibrium swelling in acetone, methanol, acetonitrile, THF, dichloromethane, using the centrifugation method. $B$ is expressed as [28]:

$B=\frac{V_{s}-V_{d}}{V_{d}} \times 100 \%$

where $V_{s}$ is the volume of the copolymer after swelling, $V_{d}$ is the volume of the dry copolymer.
2.3 Preparation of aromatic methacrylate monomers

The synthesis of aromatic methacrylates was performed as follows. The synthesis was carried out in a $500 \mathrm{~cm}^{3}$ round bottomed flask equipped with a thermometer and mechanical stirrer. To the flask, $11 \mathrm{~g}(0.1 \mathrm{~mol})$ of benzeno1,2-diol, $150 \mathrm{~cm}^{3}$ of chloroform and $24.28 \mathrm{~g}(0.24 \mathrm{~mol})$ of triethylamine $\left((\mathrm{Et})_{3} \mathrm{~N}\right)$ were added. When the benzeno-1,2diol was dissolved the temperature of the mixture was reduced to $5{ }^{\circ} \mathrm{C}$. Then $25.1 \mathrm{~g}(0.24 \mathrm{~mol})$ of methacryloyl chloride was dropped to the stirred mixture. The temperature of the reaction mixture was maintained at $3-5{ }^{\circ} \mathrm{C}$ by external cooling. After the addition of methacryloyl chloride, stirring was continued for an hour in $5^{\circ} \mathrm{C}$, and then for an hour in the room temperature. When the reaction was over, the residue of triethylamine hydrochloride was filtrated and the residual liquid was washed twice with water. The organic layer was dried over magnesium sulfate and the chloroform was distilled at low pressure. Then the crude product was purified on the chromatographic column packed with silica gel (diameter 0.0063-0.200 mm); dichloromethane was used as an eluent. The next three methacrylate compounds were synthesised in the same way. A detailed synthesis recipe of $\mathrm{MB}, 1,2 \mathrm{DMB}, 1,3 \mathrm{DMB}$ and $1,4 \mathrm{DMB}$ monomers is presented in Table 1 . The chemical structures of the new compounds were confirmed by spectroscopic methods and elemental analysis.

$M B \quad$ Elem. Anal.: calc. for $\mathrm{C}_{10} \mathrm{H}_{10} \mathrm{O}_{2}$ : C, 74.05; H, 6.21; O, 19.74. Found: C, 60.85; H, 6.71; O, 32.44. FTIR (thin film, $\left.\mathrm{cm}^{-1}\right)$ : $1740(\mathrm{C}=\mathrm{O}), 1636(\mathrm{C}=\mathrm{C}), 1142(\mathrm{C}-\mathrm{O}-\mathrm{C})$, 1490 (phenyl ring); ${ }^{1} \mathrm{H} \mathrm{NMR}\left(300 \mathrm{MHz}, \mathrm{CDCl}_{3}, \delta, \mathrm{ppm}\right)$ : $2.06(\mathrm{~m}, 3 \mathrm{H}), 5.75(\mathrm{~m}, 1 \mathrm{H}), 6.35(\mathrm{~m}, 1 \mathrm{H}), 7.09(\mathrm{~m}, 2 \mathrm{H})$, $7.23(\mathrm{~m}, 1 \mathrm{H}), 7.39(\mathrm{~m}, 2 \mathrm{H}) ;{ }^{13} \mathrm{C} \mathrm{NMR}\left(75 \mathrm{MHz}, \mathrm{CDCl}_{3}, \delta\right.$, ppm): $18.45\left(-\mathrm{CH}_{3}\right), 121.68$ (2ArC), 125.79 (ArC), 127.23 $\left(=\mathrm{CH}_{2}\right), 129.47$ (2ArC), 135.99 (=C), 151.03 (ArC), 165.91 $(\mathrm{C}=\mathrm{O})$; GC-MS (m/z): calc for $\mathrm{C}_{13} \mathrm{H}_{16} \mathrm{O}_{4}, 236.26$; found, 236.

1,2DMB Elem. Anal.: calc. for $\mathrm{C}_{14} \mathrm{H}_{14} \mathrm{O}_{4}: \mathrm{C}, 68.28 ; \mathrm{H}$, 5.73; O, 25.99. Found: C, 68.04; H, 5.44; O, 26.52. FTIR (thin film, $\left.\mathrm{cm}^{-1}\right)$ : $1746(\mathrm{C}=\mathrm{O}), 1637,1600(\mathrm{C}=\mathrm{C}), 1128$ (C-O-C), 1498, 752 (phenyl ring); ${ }^{1} \mathrm{H}$ NMR $(300 \mathrm{MHz}$, $\left.\mathrm{CDCl}_{3}, \delta, \mathrm{ppm}\right): 2.01(\mathrm{~m}, 6 \mathrm{H}), 5.72(\mathrm{~m}, 2 \mathrm{H}), 6.28(\mathrm{~m}, 2 \mathrm{H})$, $7.26(\mathrm{~m}, 4 \mathrm{H}) ;{ }^{13} \mathrm{C} \mathrm{NMR}\left(75 \mathrm{MHz}, \mathrm{CDCl}_{3}, \delta, \mathrm{ppm}\right): 18.33$ $\left(2-\mathrm{CH}_{3}\right), 123.44$ (2ArC), $126.67(2 \mathrm{ArC}), 127.65\left(2=\mathrm{CH}_{2}\right)$, 135.30 (2=C), 142.51 (2ArC), 164.79 (2C=O); GC-MS $(\mathrm{m} / \mathrm{z})$ : calc for $\mathrm{C}_{14} \mathrm{H}_{14} \mathrm{O}_{4}, 246,26$; found 246 .

1,3DMB Elem. Anal.: calc. for $\mathrm{C}_{14} \mathrm{H}_{14} \mathrm{O}_{4}: \mathrm{C}, 68.28 ; \mathrm{H}$, 5.73; O, 25.99. Found: C, 68.03; H, 5.47; O, 26.5. FTIR (thin film, $\left.\mathrm{cm}^{-1}\right): 1732(\mathrm{C}=\mathrm{O}), 1638(\mathrm{C}=\mathrm{C}), 1150(\mathrm{C}-\mathrm{O}-\mathrm{C})$, 1505, 894 (phenyl ring); ${ }^{1} \mathrm{H}$ NMR (300 $\mathrm{MHz}, \mathrm{CDCl}_{3}, \delta$, ppm): $2.05(\mathrm{~m}, 6 \mathrm{H}), 5.77(\mathrm{~m}, 2 \mathrm{H}), 6.34(\mathrm{~m}, 2 \mathrm{H}), 7.01$ 
Table 1 Synthesis of aromatic methacrylate monomers

Substrate $(\mathrm{S})$

$S$ substrate, $\mathrm{MCl}$ methacryloyl chloride, $(E t)_{3} \mathrm{~N}$ triethylamine, $\mathrm{CC}$ column chromatography

$(\mathrm{m}, 2 \mathrm{H}), 7.05(\mathrm{~m}, 1 \mathrm{H}), 7.39(\mathrm{~m}, 1 \mathrm{H}) ;{ }^{13} \mathrm{C}$ NMR $(75 \mathrm{MHz}$, $\left.\mathrm{CDCl}_{3}, \delta, \mathrm{ppm}\right): 18.41\left(2-\mathrm{CH}_{3}\right), 115.68(2 \mathrm{ArC}), 119.04$ $(\mathrm{ArC}), 127.59\left(2=\mathrm{CH}_{2}\right), 129.76(\mathrm{ArC}), 135.76 \quad(2=\mathrm{C})$, $151.48(2 \mathrm{ArC}), 165.51(2 \mathrm{C}=\mathrm{O})$; GC-MS $(\mathrm{m} / \mathrm{z})$ : calc for $\mathrm{C}_{14} \mathrm{H}_{14} \mathrm{O}_{4}, 246,26$; found 246.

1,4DMB Elem. Anal.: calc. for $\mathrm{C}_{14} \mathrm{H}_{14} \mathrm{O}_{4}: \mathrm{C}, 68.28 ; \mathrm{H}$, 5.73; O, 25.99. Found: C, 67.99; H, 5.49; O, 26.52. FTIR $\left(\mathrm{cm}^{-1}\right): 1741(\mathrm{C}=\mathrm{O}), 1636,1606(\mathrm{C}=\mathrm{C}), 1131(\mathrm{C}-\mathrm{O}-\mathrm{C})$, 1453, 810 (phenyl ring); ${ }^{1} \mathrm{H}$ NMR $\left(300 \mathrm{MHz}, \mathrm{CDCl}_{3}, \delta\right.$, ppm): $2.06(\mathrm{~m}, 6 \mathrm{H}), 5.76(\mathrm{~m}, 2 \mathrm{H}), 6.35(\mathrm{~m}, 2 \mathrm{H}), 7.15(\mathrm{~m}$, $4 \mathrm{H}) ;{ }^{13} \mathrm{C} \mathrm{NMR}\left(75 \mathrm{MHz}, \mathrm{CDCl}_{3}, \delta, \mathrm{ppm}\right): 18.46\left(2-\mathrm{CH}_{3}\right)$, 122.53 (4ArC), $127.47\left(2=\mathrm{CH}_{2}\right), 135.86$ (2=C), 148.36 (2ArC), $165.78(2 \mathrm{C}=\mathrm{O})$; GC-MS $(\mathrm{m} / \mathrm{z})$ : calc for $\mathrm{C}_{14} \mathrm{H}_{14} \mathrm{O}_{4}$, 246,26; found 246 .

\subsection{Preparation of microspheric copolymers}

Copolymers in the form of porous microspheres were produced by suspension-emulsion polymerisation of aromatic methacrylate monomers and TRIM. In each case, $195 \mathrm{~cm}^{3}$ of redistilled water and $2.2 \mathrm{~g}$ of bis (2-ethylhexyl) sulfosuccinate sodium salt (surfactant) were stirred for $1 \mathrm{~h}$ at $80{ }^{\circ} \mathrm{C}$ in a three-necked flask fitted with a stirrer, a water condenser and a thermometer. Then the solution containing $15 \mathrm{~g}$ of the mixture of aromatic methacrylate monomer and TRIM (an equivalent mole fraction of monomers), and $0.1 \mathrm{~g}$ of $\alpha, \alpha^{\prime}$-azoisobisbutyronitrile (initiator) in the solution of pore-forming diluents (toluene and decan-1-ol) were added to the aqueous medium while stirring (Table 2). Copolymerisation was performed for $15 \mathrm{~h}$ at $80{ }^{\circ} \mathrm{C}$. Porous beads that formed in this process were filtered, washed with distilled water, dried and extracted in a Soxhlet apparatus with boiling acetone, toluene and methanol. Fractions of 5-15 $\mu \mathrm{m}$ of appropriate microspheres used in further studies were isolated by sedimentation and decantation from acetone. The screening procedure was controlled by microscopic examination.

\section{Results and discussion}

The synthesis of the aromatic methacrylate monomers: methacryloiloxybenzene (MB), 1,2-dimethacryloiloxybenzene (1,2DMB), 1,3-dimethacryloiloxybenzene (1,3DMB) and 1,4-dimethacryloiloxybenzene (1,4DMB) was based on the reaction of methacryloyl chloride with phenol and its hydroxyl derivates in the presence of triethylamine used as catalyst. The method of reaction was based in part on the work of Maciejewska and Gawdzik [29, 30]. The reaction scheme for the synthesis of new aromatic methacrylates on the example of 1,2DMB synthesis is shown in Fig. 1.

Chemical structures of as synthesised methacrylate monomers were confirmed by spectroscopic methods. MB monomer is a difunctional compound, whereas 1,2DMB, 
Table 2 Copolymerisation recipe

\begin{tabular}{|c|c|c|c|c|c|}
\hline No. & $\begin{array}{l}\text { Methacrylic } \\
\text { ester }(g)\end{array}$ & TRIM (g) & Initiator (g) & Toluene (ml) & Decan-1-ol (ml) \\
\hline \multicolumn{6}{|c|}{ MB-TRIM } \\
\hline A & 4.86 & 10.14 & 0.15 & 22 & 0 \\
\hline B & 4.86 & 10.14 & 0.15 & 19 & 3 \\
\hline $\mathrm{C}$ & 4.86 & 10.14 & 0.15 & 11 & 11 \\
\hline \multicolumn{6}{|c|}{ 1,2DMB-TRIM } \\
\hline A & 6.32 & 8.68 & 0.15 & 22 & 0 \\
\hline B & 6.32 & 8.68 & 0.15 & 19 & 3 \\
\hline $\mathrm{C}$ & 6.32 & 8.68 & 0.15 & 11 & 11 \\
\hline \multicolumn{6}{|c|}{ 1,3DMB-TRIM } \\
\hline A & 6.32 & 8.68 & 0.15 & 22 & 0 \\
\hline B & 6.32 & 8.68 & 0.15 & 19 & 3 \\
\hline $\mathrm{C}$ & 6.32 & 8.68 & 0.15 & 11 & 11 \\
\hline \multicolumn{6}{|c|}{ 1,4DMB-TRIM } \\
\hline A & 6.32 & 8.68 & 0.15 & 22 & 0 \\
\hline B & 6.32 & 8.68 & 0.15 & 19 & 3 \\
\hline $\mathrm{C}$ & 6.32 & 8.68 & 0.15 & 11 & 11 \\
\hline
\end{tabular}

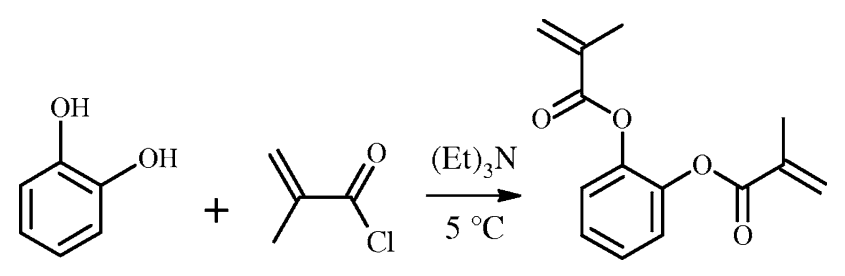

Fig. 1 Synthesis of 1,2-dimethacryloiloxybenzene (1,2DMB)

1,3DMB and 1,4DMB are tetrafunctional. These compounds are isomers possessing aromatic and also aliphatic fragments in their structures. Such composition of monomers is interesting due to the formation of copolymers with different selectivity next applied as HPLC packings. Aromatic rings are responsible for the good thermal and mechanical stability of microspheres whereas methacrylate fragments decrease their hydrophobic character.

\subsection{Preparation of porous microspheres}

Our aim in this study was to synthesise a new group of functional monomers suitable for the production of porous microspheres that could be used as HPLC packing. Porous copolymers MB-TRIM, 1,2DMB-TRIM, 1,3DMB-TRIM and 1,4DMB-TRIM were obtained by suspension-emulsion polymerisation. Using this method, products in the form of microspheres were obtained. Their diameters were in the range $2-50 \mu \mathrm{m}$. Figure 2 presents SEM images of exemplary products. As can be seen, the obtained beads are characterized by broad particle size distribution. Particle size distribution of the obtained microspheres was evaluated with the use of laser diffraction method. In Table 3 the statistic data of particle size distribution of the copolymers obtained in the presence of $85 \%$ toluene in the mixture with decan-1-ol (copolymerisations marked as B) are presented, whereas Fig. 3 shows particle size distribution by volume. $d(0.1)$ is the size of particle (in microns) below which $10 \%$ of the sample lies, $d(0.9)$ is the size of particle below which $90 \%$ of the sample lies, $d(0.5)$ is the size in microns at which $50 \%$ of the sample is smaller and $50 \%$ is larger. This value refers to mass median diameters (MMD). Moreover, the width of size distribution (span) was calculated. The narrower the distribution, the smaller the span becomes. The span is defined as:

Span $=\frac{d(0.9)-d(0.1)}{d(0.5)}$

From the data presented one can conclude that the type of aromatic methacrylate monomer does not significantly influence the average diameter of the synthesised microspheres. Slight differences in span values show that in the case of MB-TRIM microspheres obtained from the difunctional comonomer MB their particle size distribution is narrower than for other microspheres synthesised from tetrafunctional aromatic comonomers.

\subsection{Structural characterization}

The chemical structure of the synthesised copolymers was studied with the use of Raman spectroscopy and ${ }^{13} \mathrm{C} \mathrm{CP}$ MAS NMR measurements. The Raman spectra of the copolymers show the following characteristic peaks presented in Table 4. On their basis we can confirm that during the copolymerisation reaction of TRIM with 

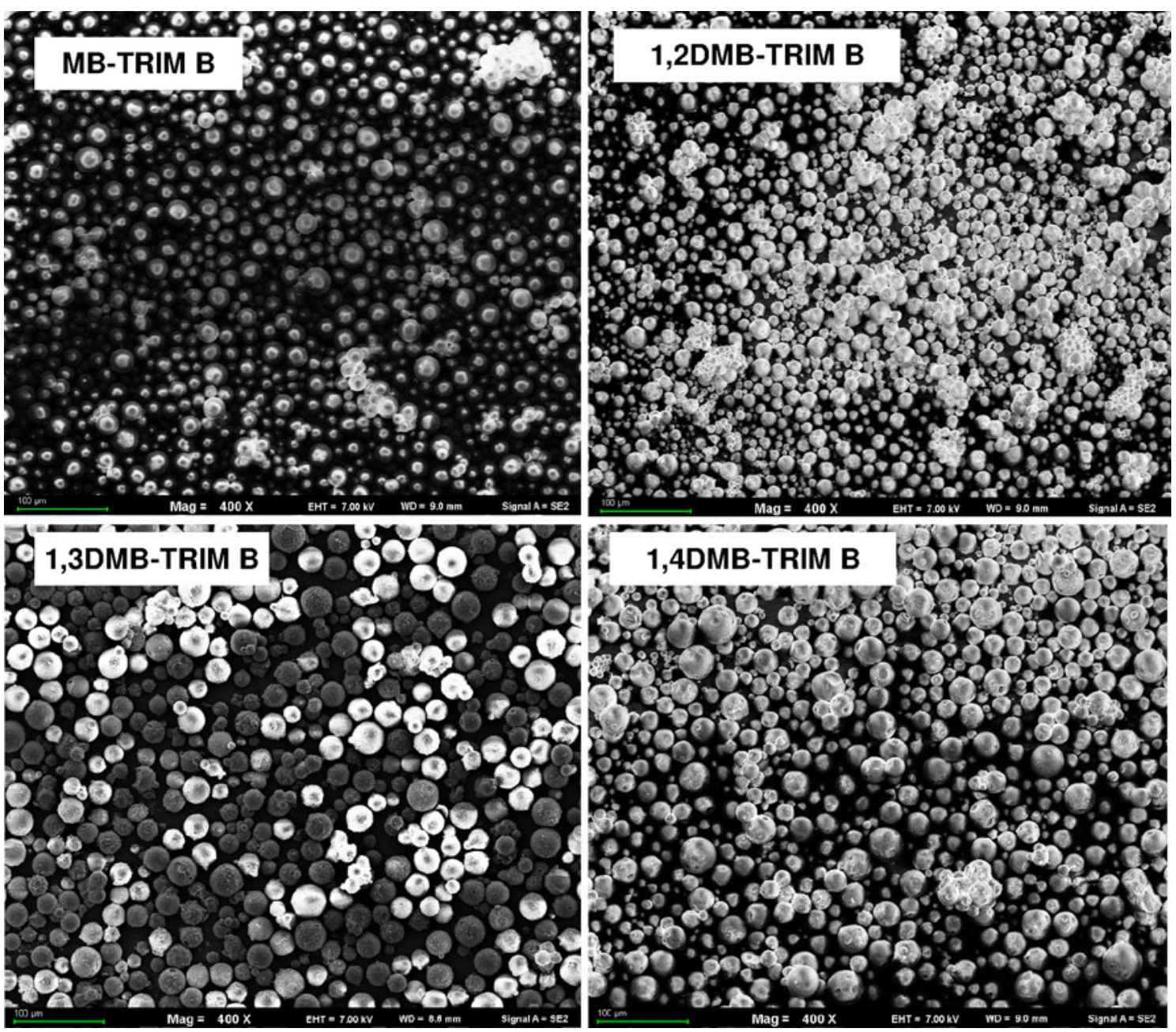

Fig. 2 SEM images of microspheres encoded as B; magnification $400 \mathrm{x}$

Table 3 The statistic data of particle size distribution

\begin{tabular}{lllll}
\hline Copolymer & $d(0.1)$ & $d(0.5)$ & $d(0.9)$ & Span \\
\hline MB-TRIM & 20.10 & 26.81 & 35.64 & 0.58 \\
1,2 DMB-TRIM & 15.93 & 22.06 & 31.48 & 0.71 \\
1,3 DMB-TRIM & 25.53 & 35.34 & 47.44 & 0.62 \\
1,4 DMB-TRIM & 16.50 & 28.39 & 41.58 & 0.88 \\
\hline
\end{tabular}

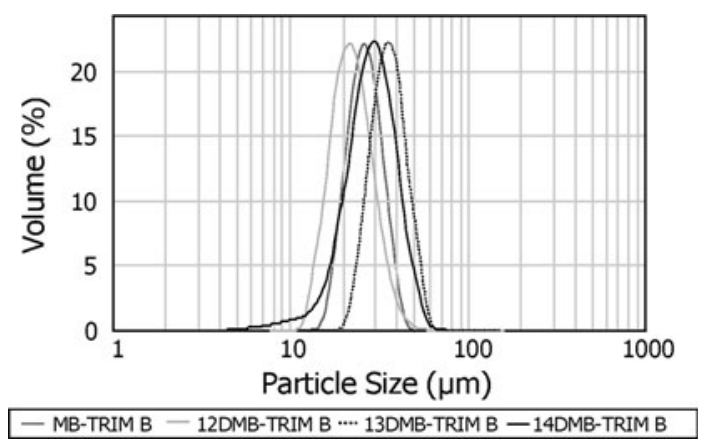

Fig. 3 Particle size distribution aromatic methacrylates copolymeric networks were built. However, the presence of the spectra peak bands at about $1,640 \mathrm{~cm}^{-1}$ suggests that unsaturated $\mathrm{C}=\mathrm{C}$ bonds still exist in copolymer structures.

CP-MAS ${ }^{13} \mathrm{C}$ NMR is the useful method for the detection of $\mathrm{C}=\mathrm{C}$ double bonds in the structure of insoluble polymers. In the unreacted methacrylate group, the carbonyl bond is conjugated with a $\mathrm{C}=\mathrm{C}$ double one, which should shift the ${ }^{13} \mathrm{C}$ carbonyl resonance about $10 \mathrm{ppm}$ upfield compared to the reacted units [31].

The ${ }^{13} \mathrm{C}$ CP-MAS NMR spectra of the studied porous materials are presented in Fig. 4. The peaks observed at 
Table 4 Assignments of the bands in the Raman spectra

\begin{tabular}{lllll}
\hline Assignment & \multicolumn{2}{l}{ Wavenumber $\left(\mathrm{cm}^{-1}\right)$} & & \\
\cline { 2 - 5 } & MB-TRIM & 1,2 DMB-TRIM & 1,3 DMB-TRIM & 1,4 DMB-TRIM \\
\hline$>\mathrm{C}=\mathrm{O}$ & 1,726 & 1,730 & 1,641 & 1,741 \\
$>\mathrm{C}=\mathrm{C}<$ & 1,641 & 1,643 & 1,405 & 1,641 \\
$>\mathrm{C}=\mathrm{CH}_{2}$ & 1,400 & 1,400 & $1,455,1,605$ & 1,407 \\
$>\mathrm{C}_{\mathrm{AR}}=\mathrm{C}_{\mathrm{AR}}<$ & $1,453,1,595$ & $1,440,1,604$ & $1,455,1,600$ \\
$-\mathrm{CH}_{3},-\mathrm{CH}_{2-}$ & 2,936 & 2,931 & 2,936 & 2,932 \\
\hline
\end{tabular}

Fig. $4{ }^{13} \mathrm{C}$ CP-MAS NMR spectra of investigated copolymers

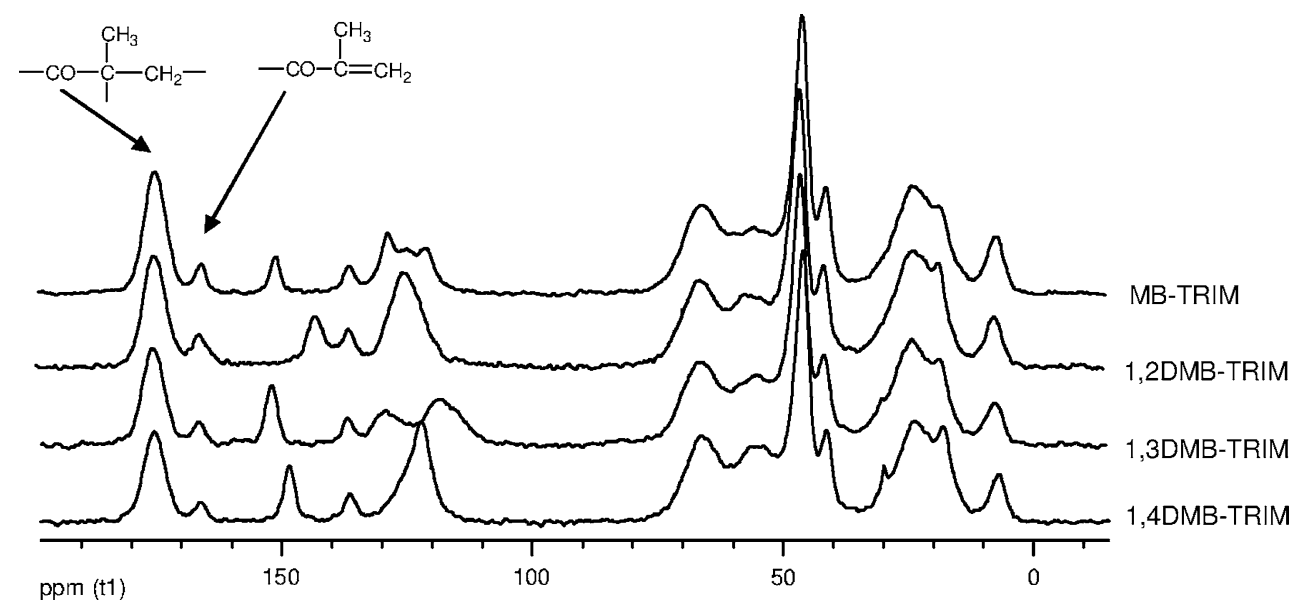

Table 5 The amount of unreacted double bonds in porous polymers on the basis of ${ }^{13} \mathrm{C}$ CP-MAS NMR measurements

\begin{tabular}{|c|c|c|c|}
\hline \multirow[t]{2}{*}{ Copolymer } & \multicolumn{2}{|l|}{ Chemical shift (ppm) } & \multirow{2}{*}{$\begin{array}{l}\text { NMR } \\
\% \text { unreacted } \\
\mathrm{C}=\mathrm{C}\end{array}$} \\
\hline & $\begin{array}{l}\mathrm{C}=\mathrm{O} \text { in reacted } \\
\text { methacrylate group }\end{array}$ & $\begin{array}{l}\mathrm{C}=\mathrm{O} \text { in unreacted } \\
\text { methacrylate group }\end{array}$ & \\
\hline MB-TRIM & 175.51 & 166.21 & 6.4 \\
\hline 1,2DMB-TRIM & 175.30 & 166.16 & 13.3 \\
\hline 1,3DMB-TRIM & 175.73 & 166.38 & 10.1 \\
\hline 1,4DMB-TRIM & 175.37 & 166.08 & 7.7 \\
\hline
\end{tabular}

about 166 and $175 \mathrm{ppm}$ correspond to carbonyl groups: one conjugated with the carbon-carbon double bond and the other nonconjugated, respectively. According to Flodin [31], quantitative ${ }^{13} \mathrm{C}$ CP-MAS NMR measurements are possible, provided the contact time is almost similar. In Table 5 the concentration of unreacted double bonds is listed. As can be seen from the presented results, about $10 \%$ of the carbon-carbon double bonds are still present in copolymer networks. Moreover, on the basis of the data given in Table 5, we can conclude that the structure of monomers influenced the conversion degree of double bonds.

\subsection{Porous structure characterization}

Copolymerisation of TRIM with synthesised monomers was performed in the presence of pore-forming diluent mixture (toluene and decan-1-ol), which ensured formation of porous polymers. The volume ratios of the diluents to the monomers and the molar ratio of the monomers were kept constant (Table 2).

In a dry state, porosity characteristic of copolymers was obtained from nitrogen adsorption-desorption measurements. Table 6 summarises the porous properties of four series of the studied copolymers prepared from mixtures containing varying percentages of pore forming diluents. In each type of copolymer one can observe that the largest pore volume and surface area was obtained for materials synthesised in the presence of $50 \%(\mathrm{v} / \mathrm{v})$ toluene (copolymer C). $S_{\text {Bet }}$ for MB-TRIM C is $235 \mathrm{~m}^{2} / \mathrm{g}$ and grows for materials obtained from tetrafunctional comonomers to $510 \mathrm{~m}^{2} / \mathrm{g}$ for $1,4 \mathrm{DMB}-\mathrm{TRIM} \mathrm{C}$. It is known that with an increase of the crosslinker concentration a specific surface area also increases, so our observation is consistent 
Table 6 Parameters characterizing the porosity of the investigated samples
$S_{B E T}$ specific surface area, $V_{p}$ total pore volume, $D_{p}$ pore diameters at the peak of PSD

\begin{tabular}{llll}
\hline Copolymer & $S_{\text {BET }}\left(\mathrm{m}^{2} / \mathrm{g}\right)$ & $V_{p}\left(\mathrm{~cm}^{3} / \mathrm{g}\right)$ & $D_{p}(\mathrm{~nm})$ \\
\hline MB-TRIM A & 185 & 0.18 & 3.2 \\
MB-TRIM B & 213 & 0.31 & 4.2 \\
MB-TRIM C & 235 & 0.36 & $3.2 / 24.5$ \\
1,2 DMB-TRIM A & 196 & 0.25 & 4.0 \\
1,2 DMB-TRIM B & 276 & 0.34 & 4.1 \\
1,2 DMB-TRIM C & 297 & 0.53 & $4.9 / 8.2$ \\
1,3 DMB-TRIM A & 327 & 0.54 & $4.0 / 8.4$ \\
1,3 DMB-TRIM B & 352 & 0.59 & $4.0 / 14.2$ \\
1,3 DMB-TRIM C & 396 & 0.81 & 18.6 \\
1,4 DMB-TRIM A & 406 & 0.36 & 4.1 \\
1,4 DMB-TRIM B & 433 & 0.51 & 4.1 \\
1,4 DMB-TRIM C & 510 & 0.92 & 15.0 \\
\hline
\end{tabular}

Table 7 Parameters of the porous structure for the studied copolymers obtained with BET and EC methods

\begin{tabular}{llll}
\hline $\begin{array}{l}\text { Specific surface } \\
\text { area }\left(\mathrm{m}^{2} / \mathrm{g}\right)\end{array}$ & $\begin{array}{l}\text { Pore volume } \\
\left(\mathrm{cm}^{3} / \mathrm{g}\right)\end{array}$ & $\begin{array}{l}\text { Volume of } \\
\text { micropores } \\
\left(\mathrm{cm}^{3} / \mathrm{g}\right)\end{array}$ & $D_{p}(\mathrm{~nm})$ \\
\hline MB-TRIM B & & & \\
BET 213 & 0.31 & 0 & 4.2 \\
EC - & 1.56 & 0.29 & $2.2 / 9.7$ \\
1,2DMB-TRIM B & & & \\
BET 276 & 0.34 & 0 & 4.1 \\
EC - & 1.78 & 0.41 & $2.2 / 15.7$ \\
1,3DMB-TRIM B & & & \\
BET 352 & 0.59 & 0 & $4.0 / 14.2$ \\
EC - & 1.36 & 0.32 & $2.1 / 15.7$ \\
1,4DMB-TRIM B & & & \\
BET 433 & 0.51 & 0 & 4.1 \\
EC - & 1.48 & 0.55 & $1.6 / 9.7$ \\
\hline
\end{tabular}

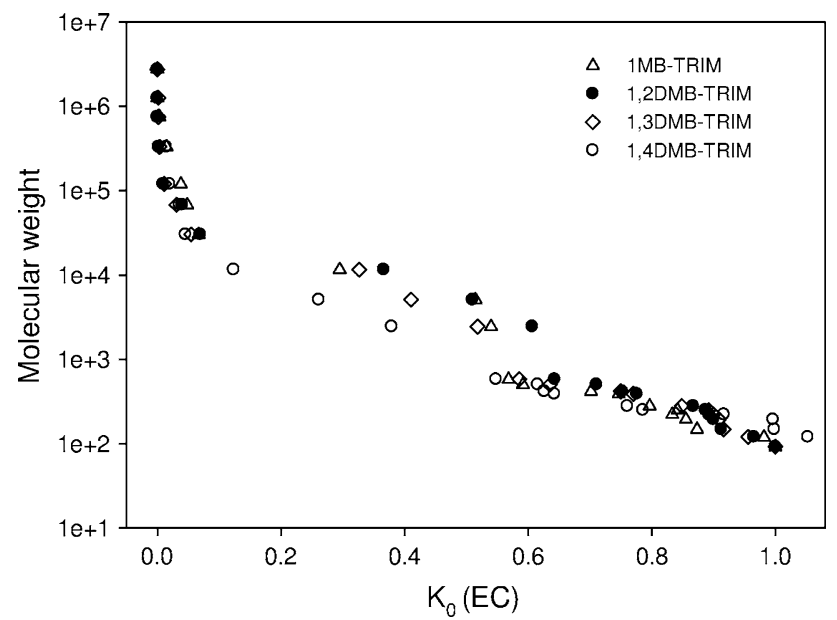

Fig. 6 EC calibration curves

with former knowledge [32, 33]. However, what is interesting, in the group of copolymers synthesised from tetrafunctional comonomers (1,2DMB, 1,3DMB, and 1,4DMB)

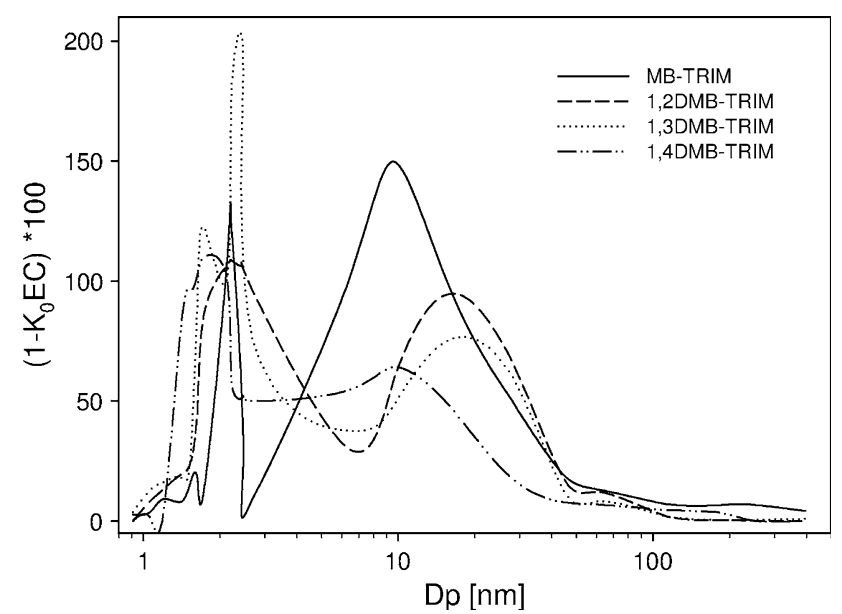

Fig. 7 EC pore size distribution 
Fig. 8 AFM images of the microspheres surfaces

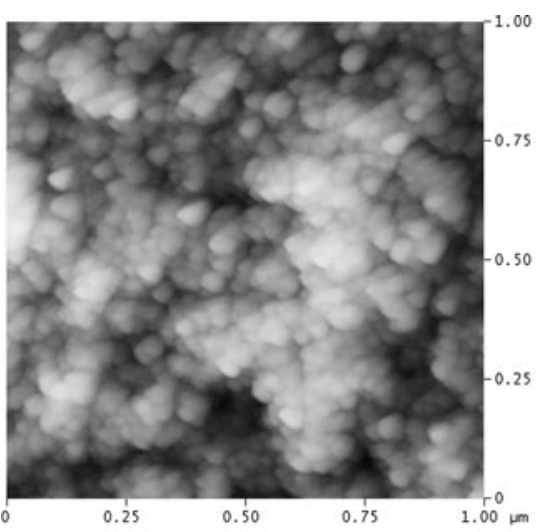

\section{MB-TRIM}

Img. $Z$ range

$77.324 \mathrm{~nm}$

Img. Mean

$0.116 \mathrm{~nm}$

Img. Raw mean

$490.49 \mathrm{~nm}$

Img. Rms (Rq)

$11.911 \mathrm{~nm}$

Img. Ra

$9.737 \mathrm{~nm}$

Img. Rmax

$73.815 \mathrm{~nm}$

Img. Srf. area

Img. Prj. Srf. area

Img. Srf. area diff

$1.168 \mu \mathrm{m}^{2}$

$999999 \mathrm{~nm}^{2}$

$16.769 \%$

Img. SAE

1.083

\section{1,2DMB-TRIM}

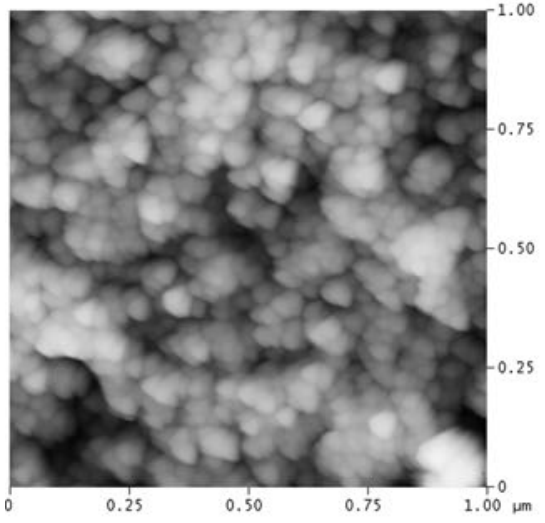

Img. $Z$ range

$87.141 \mathrm{~nm}$

Img. Mean

$0.117 \mathrm{~nm}$

Img. Raw mean

$174.17 \mathrm{~nm}$

Img. Rms (Rq)

$12.022 \mathrm{~nm}$

Img. Ra

$9.558 \mathrm{~nm}$

Img. Rmax

$87.039 \mathrm{~nm}$

Img. Srf. area

$1.191 \mu \mathrm{m}^{2}$

Img. Prj. Srf. area

Img. Srf. area diff

$999999 \mathrm{~nm}^{2}$

Img. SAE

$19.059 \%$

1.090

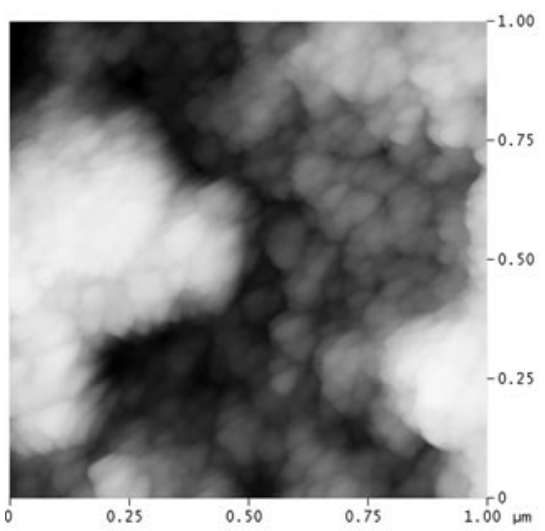

\section{1,3DMB-TRIM}

Img. $Z$ range

$158.92 \mathrm{~nm}$

Img. Mean

$0.108 \mathrm{~nm}$

Img. Raw mean

$97.457 \mathrm{~nm}$

Img. Rms (Rq)

$30.625 \mathrm{~nm}$

Img. Ra

$25.826 \mathrm{~nm}$

Img. Rmax

$154.52 \mathrm{~nm}$

Img. Srf. area

Img. Prj. Srf. area

$1.174 \mu \mathrm{m}^{2}$

$999999 \mathrm{~nm}^{2}$

Img. Srf. area diff

$17.413 \%$

Img. SAE

1.091

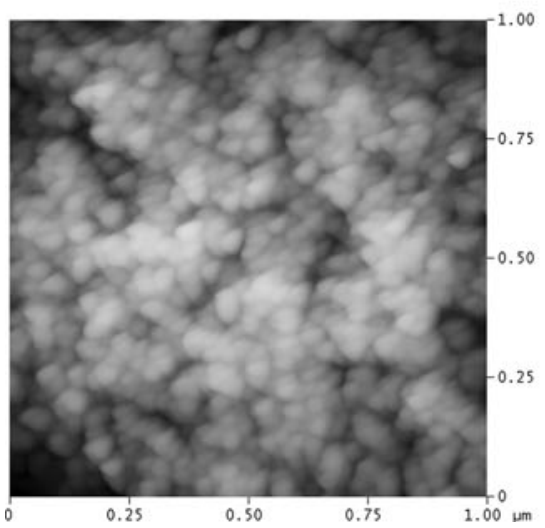

\section{1,4DMB-TRIM}

Img. $Z$ range

$81.972 \mathrm{~nm}$

Img. Mean

$0.106 \mathrm{~nm}$

Img. Raw mean

$183.74 \mathrm{~nm}$

Img. Rms (Rq)

$10.693 \mathrm{~nm}$

Img. Ra

$8.574 \mathrm{~nm}$

Img. Rmax

$81.175 \mathrm{~nm}$

Img. Srf. area

$1.113 \mu \mathrm{m}^{2}$

Img. Prj. Srf. area

$999999 \mathrm{~nm}^{2}$

Img. Srf. area diff

$11.263 \%$

Img. SAE

1.053 
Table 8 Swelling studies

\begin{tabular}{llllll}
\hline Copolymer & \multicolumn{5}{l}{ Swellability coefficient $(\%)$} \\
\cline { 2 - 6 } & Hexane & Toluene & Acetone & Methanol & THF \\
\hline MB-TRIM & 8 & 15 & 19 & 16 & 22 \\
1,2DMB-TRIM & 7 & 14 & 21 & 21 & 20 \\
1,3DMB-TRIM & 5 & 18 & 20 & 15 & 18 \\
1,4DMB-TRIM & 5 & 18 & 20 & 18 & 16 \\
\hline
\end{tabular}

that are isomers, we can observe a new correlation between the structure of the monomers and a specific surface area. With a decrease of the steric hindrance in isomeric monomers we can obtain polymers with increasing porous structure. Networks formed by the 1,4DMB comonomer with TRIM have higher crosslinking density than those formed by $1,2 \mathrm{DMB}$ comonomer, which is convergent with the presented CP-MAS NMR studies. In Fig. 5 pore size distributions (PSD) for MB-TRIM B, 1,2DMB-TRIM B, 1,3DMB-TRIM $\mathrm{B}$ and 1,4DMB-TRIM $\mathrm{B}$ are presented. For all the studied copolymers the pore diameter calculated from PSD is about $4 \mathrm{~nm}$, which means that mesopores are present in these microspheres. Except for the 1,3DMBTRIM B microspheres, PSD curves have unimodal character. The second peak on its curve has a maximum at $14 \mathrm{~nm}$, which suggests presence of two types of mesopores in this material.

On the basis of the data given in Table 6, we decided to choose materials for next studies. Since copolymers marked as B, obtained in the presence of $85 \%(\mathrm{v} / \mathrm{v})$ toluene, have developed porous structure and similar PSDs, they were chosen for further studies.

$\mathrm{N}_{2}$ adsorption-desorption method characterizes the beads in the dry state. To complete the results of porous structure, inverse size exclusion chromatography was used to determine the porous properties of the beads in a swollen state, which is more typical of their use [34]. The EC calibration curves for the studied copolymers measured in tetrahydrofuran with toluene, alkylphenones, phthalates and polystyrene standards are shown in Fig. 6.

All the studied microspheres have few large macropores as indicated by the lack of separation of standards with molecular weight exceeding $10^{5}$. In contrast more than $80 \%$ of the total pore volume is available for the separation of polystyrene molecules with a hydrodynamic size smaller than $15 \mathrm{~nm}$, a value that corresponds to a molecular weight of less than $10^{5}$. Comparison of surface parameters obtained by nitrogen adsorption-desorption and inverse size exclusion chromatography methods is presented in Table 7. Pore volume for the swollen copolymers is significantly larger than that for the dry copolymers. In the swollen state micropores are revealed in their internal structure, whereas for dry copolymers they are absent.
Contribution of micropores in the studied materials is close to $20 \%$, and for 1,4DMB-TRIM exceeds even $30 \%$. The pore size distribution from EC measurements is presented in Fig. 7. These curves illustrate a different pore size distribution from nitrogen adsorption-desorption. The bimodal character of PSD curves is shown by two maximums related to the presence of micropores (about $2 \mathrm{~nm}$ ) and mesopores in microspheres [24, 27].

In Fig. 8 the fragments of the surface of the studied microspheres are presented. In contact-mode AFM images the porous structure of these materials is well visible. As can be seen, polymerisation in the presence of pore-forming diluents provides copolymeric networks consisting of particle agglomerates of various sizes. The root mean square (RMS) roughness for the studied copolymers is close to $10 \mathrm{~nm}$ and indicate that their surface is rough $[15,35]$.

\subsection{Swelling studies}

In Table 8 the results of swelling studies for copolymers marked B are presented. In determining the swelling properties of microspheres, solvents with different chemical character were used.

The values of swellability coefficients for copolymeric materials vary from 5 to $24 \%$. Their largest values are observed in acetone, whereas in nonpolar aliphatic hexane swellability coefficients are the smallest. The ability to swell of all studied materials is similar. Discussed microspheres have similar chemical structures, and their networks are crosslinked. Generally, crosslinked polymers have a low tendency to swell, but the presence of functional groups in the discussed materials causes network interactions with appropriate solvents. Solvents of the proton-donor and proton-acceptor type interact specifically with ester groups present in copolymers. In addition, confirmed presence of micropores in the microspheres structures allows solvents to penetrate their networks readily.

\section{Conclusions}

The synthesis, chemical characterization and properties of a new type of microspheric methacrylate copolymers were presented. New aromatic monomers MB, 1,2DMB, 1,3DMB and 1,4DMB were synthesised and applied to the synthesis of porous microspheres.

A permanent porous structure of the studied materials was obtained through the use of pore forming diluents (toluene and decan-1-ol). On the basis of conducted investigation the following conclusion could be drawn. Despite similarity in the chemical structure of aromatic methacrylate monomers, some differences and correlation 
between the molecular structure of monomers and the physicochemical properties of new copolymeric networks were seen. The new MB-TRIM, 1,2DMB-TRIM, 1,3DMB-TRIM and 1,4DMB-TRIM porous microspheres obtained can be utilised as functional stationary phases in liquid chromatography. Because of their chemical character they can be used in HPLC in both normal and reversed phases.

Open Access This article is distributed under the terms of the Creative Commons Attribution License which permits any use, distribution, and reproduction in any medium, provided the original author(s) and the source are credited.

\section{References}

1. B. Buszewski, M. Jaćkowska, S. Bocian, P. Kosobucki, B. Gawdzik, J. Sep. Sci. 34, 601 (2011)

2. M. Slater, M. Snauko, F. Svec, J.M.J. Frechet, Anal. Chem. 78, 4969 (2006)

3. D. Jermakowicz-Bartkowiak, B.N. Kolarz, React. Funct. Polym. 71, 95 (2011)

4. D. Yuan, B. Huang, Catal. Commun. 18, 126 (2012)

5. V. Bulmuş, K. Kesenci, E. Pişkin, React. Funct. Polym. 38, 1 (1998)

6. B. Podkościelna, J. Appl. Polym. Sci. 120, 3020 (2011)

7. R.A. Prasath, M.T. Gokmen, P. Espeel, F.E. Du Prez, Polym. Chem. 1, 685 (2010)

8. A. Ferreira, M. Bigan, D. Blondeau, React. Funct. Polym. 56, 123 (2003)

9. M. Grochowicz, A. Bartnicki, B. Gawdzik, J. Appl. Polym. Sci. 107, 3718 (2008)

10. M. Maciejewska, J. Appl. Polym. Sci. 124, 568 (2012)

11. M. Grochowicz, B. Gawdzik, React. Funct. Polym. 71, 625 (2011)

12. M. Maciejewska, J. Osypiuk, B. Gawdzik, J. Polym. Sci. Part A: Polym. Chem. 43, 3049 (2005)
13. B. Podkościelna, B. Gawdzik, A. Bartnicki, J. Polym. Sci. Part A: Polym. Chem. 44, 7014 (2006)

14. M. Grochowicz, A. Bartnicki, B. Gawdzik, J. Polym. Sci. Part A: Polym. Chem. 46, 6165 (2008)

15. M. Grochowicz, B. Gawdzik, A. Bartnicki, J. Polym. Sci. Part A: Polym. Chem. 47, 3190 (2009)

16. M.J. Benes, D. Horak, F. Svec, J. Sep. Sci. 28, 1855 (2005)

17. C. Garcia-Diego, J. Cuellar, Ind. Eng. Chem. Res. 44, 8237 (2005)

18. K.A. Kun, R. Kunin, J. Polym. Sci. Part B: Polym. Lett. 2, 587 (1964)

19. K.A. Kun, R. Kunin, J. Polym. Sci. Part C: Polym. Symp. 16, 1457 (1967)

20. B. Gawdzik, J. Gawdzik, U. Czerwińska-Bil, Chromatographia 26, 399 (1988)

21. S. Brunauer, P.H. Emmet, E. Teller, J. Am. Chem. Soc. 60, 309 (1938)

22. E.P. Barrett, L.G. Joyner, P.P. Halenda, J. Am. Chem. Soc. 73, 373 (1951)

23. I. Halasz, K. Martin, Ber Bunsen-Ges Phys. Chem. 79, 731 (1975)

24. F. Nevejans, M. Verzele, J. Chromatogr. 350, 145 (1985)

25. B. Gawdzik, J. Osypiuk, Chromatographia 54, 595 (2001)

26. B. Podkościelna, B. Gawdzik, A. Bartnicki, J. Polym. Sci. Part A: Polym. Chem. 44, 7014 (2006)

27. B. Gawdzik, Chromatographia 31, 21 (1991)

28. A. Tuncel, E. Piskin, J. Appl. Polym. Sci. 62, 789 (1996)

29. B. Gawdzik, M. Maciejewska, J. Polym. Sci. Part A: Polym. Chem. 40, 3079 (2002)

30. M. Maciejewska, B. Gawdzik, J. Appl. Polym. Sci. 95, 863 (2005)

31. J.E. Rosenberg, P. Flodin, Macromolecules 19, 1543 (1986)

32. C.M. Cheng, F.J. Micale, J.W. Vanderhoff, M.S. El-Aasser, J. Polym. Sci. Part A: Polym. Chem. 30, 235 (1992)

33. M. Kedem, S. Margel, J. Polym. Sci. Part A: Polym. Chem. 40, $1342(2002)$

34. N. Tanaka, K. Kimata, Y. Mikawa, K. Hosoya, T. Araki, Y. Ohtus, Y. Shiojima, R. Tsuboi, H. Tsuchiya, J. Chromatogr. 535, $13(1990)$

35. E.J. Thoreson, J. Martin, J. Burnham, J. Colloid Interface Sci. 298, 94 (2006) 